\title{
Tissue remodeling macrophages morphologically dominate at the interface of polypropylene surgical meshes in the human abdomen
}

\author{
A. Dievernich ${ }^{1}$ (D) P. Achenbach ${ }^{2} \cdot$ L. Davies $^{3} \cdot$ U. Klinge $^{1}$
}

Received: 29 June 2020 / Accepted: 23 September 2020 / Published online: 8 October 2020

(c) The Author(s) 2020

\begin{abstract}
Background Mesh implants are widely used to reinforce the abdominal wall, although the inevitable inflammatory foreign body reaction (FBR) at the interface leads to complications. Macrophages are suspected to regulate the subsequent scar formation, but it is still unclear whether adequate fibrous scar formation with collagen deposition depends mainly on the presence of M1 or M2 macrophages.

Methods This study investigated the FBR to seven human polypropylene meshes, which were removed after a median incorporation time of 1 year due to the primary complaint of recurrence. Using immunofluorescence, the FBR was examined in six regional zones with increasing distance from the mesh fibers up to $350 \mu \mathrm{m}$, based on the cell densities, macrophage M1 (CD86) and M2 (CD163, CD206) phenotypes, deposition of collagen-I and -III, and expression of matrix metalloproteinase-2 (MMP-2) and -8 as indicator of collagen degradation.

Results All mesh-tissue complexes demonstrated a decrease in cell density and macrophages with distance to the mesh fibers. Overall, about $60 \%$ of the macrophages presented an M2 phenotype, whereas only $6 \%$ an M1 phenotype. Over $70 \%$ of macrophages showed co-expression with collagen-I or -III and over 50\% with MMP-2.

Conclusions The chronic FBR to polypropylene meshes is associated with an M2 macrophage response, which is accompanied by collagen deposition and MMP-2 expression. These findings challenge the idea that mainly M1 macrophages are related to inflammation and highlights that iatrogenic attempts to polarize these cells towards the M2 phenotype may not be a solution to ameliorate the long-term foreign body reaction.
\end{abstract}

Keywords Foreign body reaction $\cdot$ Macrophage $\cdot$ Collagen $\cdot$ Mesh $\cdot$ Fluorescence microscopy

\section{Introduction}

Electronic supplementary material The online version of this article (https://doi.org/10.1007/s10029-020-02315-2) contains supplementary material, which is available to authorized users.

\section{A. Dievernich}

adievernich@web.de

1 Department of General, Visceral and Transplant Surgery, RWTH Aachen University Hospital, Pauwelsstraße 30, 52074 Aachen, Germany

2 Institute of Neuropathology, RWTH Aachen University Hospital, Aachen, Germany

3 Division of Infection and Immunity, Cardiff University, Cardiff, UK
Currently, textile mesh structures made of polypropylene are widely used to reinforce a hernia repair in the abdominal wall. The tissue reaction to the implants leads to the formation of a foreign body granuloma. Here, the mesh fibers are surrounded by dense layers of inflammatory cells with accompanying fibrotic encapsulation that shields the mesh from the surrounding tissue. After early recruitment of neutrophils, macrophages become the predominant cell mediator and are suspected to regulate the subsequent scar formation [1].

In 1992, Stein et al. demonstrated that IL-4 is an alternative activator for macrophages [2]. His findings later led to the separation of activated macrophages into two main populations, designated classically activated (M1) and alternatively activated (M2) [3]. This nomenclature is too 
simplistic and does not accurately describe the heterogeneity of macrophage phenotype in complex environments in situ; however, it remains useful for clinical assessment. Typically, in humans, 'M1' macrophages express the cell surface marker CD86 and produce high levels of proinflammatory cytokines. A prolonged or persistent M1 response can damage the tissue. In contrast, 'M2' macrophages encompass several different macrophage populations, which have overlapping marker expression and are relatively anti-inflammatory [4]. Though, two key markers are the mannose receptor CD206 and the scavenger receptor CD163. These cells produce lower amounts of proinflammatory cytokines and are considered to play a primary physiological role in promoting constructive healing and tissue remodeling [5]; hence, being termed by some as wound healing macrophages. However, it is recognized that a long-lasting strong 'M2' response can lead to excessive collagen formation, resulting in fibrosis $[1,6]$.

Experimental studies in animals with meshes have demonstrated that at least within 12 weeks after implantation, mainly M1 $\left(\mathrm{CD}^{2} 6^{+}\right)$macrophages surrounded the mesh fibers and formed the foreign body granuloma $[7,8]$. The predominance of these cells was confirmed by Nolfi et al. at human mesh explants from the pelvic floor, which were explanted because of inflammatory or fibrotic complications [9].

However, due to several conflicting studies, it still is not clear whether adequate fibrous scar formation with collagen deposition depends mainly on the presence of M1 or M2 macrophages [10]. In a mouse model, a shift from the M1 towards M2 phenotype led to a reduced fibrotic response [11], whereas in another mouse model the M2 phenotype was responsible for the development of fibrosis in the lung, likely by promoting myofibroblast differentiation of mesenchymal stem cells [12]. This highlights the need for further studies to determine the role of macrophages in both collagen deposition and degradation.

Therefore, we investigated whether M1 or M2 macrophages are related to local deposition of collagen-I and -III at seven polypropylene (PP) meshes, which were explanted from the abdominal wall due to recurrences. We examined the foreign body reaction to the meshes using cell densities, defined as cells per $\mathrm{mm}^{2}$, and the percentages of macrophage populations in six regional zones with increasing distance from the mesh up to $350 \mu \mathrm{m}$. In addition, we quantified the collagen deposition in each regional zone and the expression of two different matrix metalloproteinases: gelatinase A (MMP-2) and neutrophil collagenase (MMP-8) as indicators of collagen degradation.

\section{Materials and methods}

We analyzed tissue sections of seven polypropylene (PP) monofilament meshes (used for the repair of abdominal wall hernias), which were explanted due to recurrences. After removal, samples were embedded in aqueous formalin solution to preserve the tissue before sectioning and further processing to FFPE blocks. Operative reports from the initial mesh surgery were reviewed, and the following meshes were recorded: 3 large pore Ultrapro®, 2 Ventralex ${ }^{\circledR}$ with a layer of PTFE, and 2 small pore plugs (Table 1). To optimize antibody dilutions and to check specificity of labeling, we used human spleen and tonsil tissues that did not display gross pathology as control tissues (Online Resource 1).

Prior to immunofluorescence staining, mesh samples were checked for the presence of characteristic cells and morphology by hematoxylin and eosin (Fig. 1). All specimens showed a typical, highly localized foreign body reaction around the mesh fibers with an inner infiltrate of predominantly mononuclear cells and an outer fibrotic capsule. Multinucleated giant cells were observed at the surface of some mesh fibers in all samples.

\section{Immunofluorescent staining}

\section{General}

All steps were performed at room temperature. Serial $2 \mu \mathrm{m}$ sections of each specimen were double labeled with monoclonal antibodies (Table 2). The order of fluorophores was always kept constant. For the first marker we always used the pan-macrophage marker CD68 labeled with fluorescein isothiocyanate (FITC). The second marker was always labeled with cyanine-5 (Cy5). The list of second markers includes CD86 (M1), CD163 and CD206 (both M2), collagen-I, collagen-III, MMP-2, and MMP-8. All antibodies were diluted with Antibody Diluent (with Background Reducing Components, Dako, Germany). Secondary antibodies were applied

Table 1 Information on the patients whose mesh samples were examined in this study

\begin{tabular}{lllll}
\hline Explant no & Mesh type & $\begin{array}{l}\text { Incorporation } \\
\text { time (years) }\end{array}$ & Gender & Age \\
\hline$\# 1$ & Ultrapro® & 0.6 & Female & 52 \\
$\# 2$ & Ultrapro® & 0.9 & Female & 34 \\
$\# 3$ & Ultrapro® & 1.3 & Female & 50 \\
$\# 4$ & Ventralex ${ }^{\circledR}$ & 1.0 & Male & 47 \\
$\# 5$ & Ventralex ${ }^{\circledR}$ & 6.0 & Female & 57 \\
$\# 6$ & Plug & 2.2 & Male & 69 \\
$\# 7$ & Plug & 4.0 & Male & 51 \\
\hline
\end{tabular}




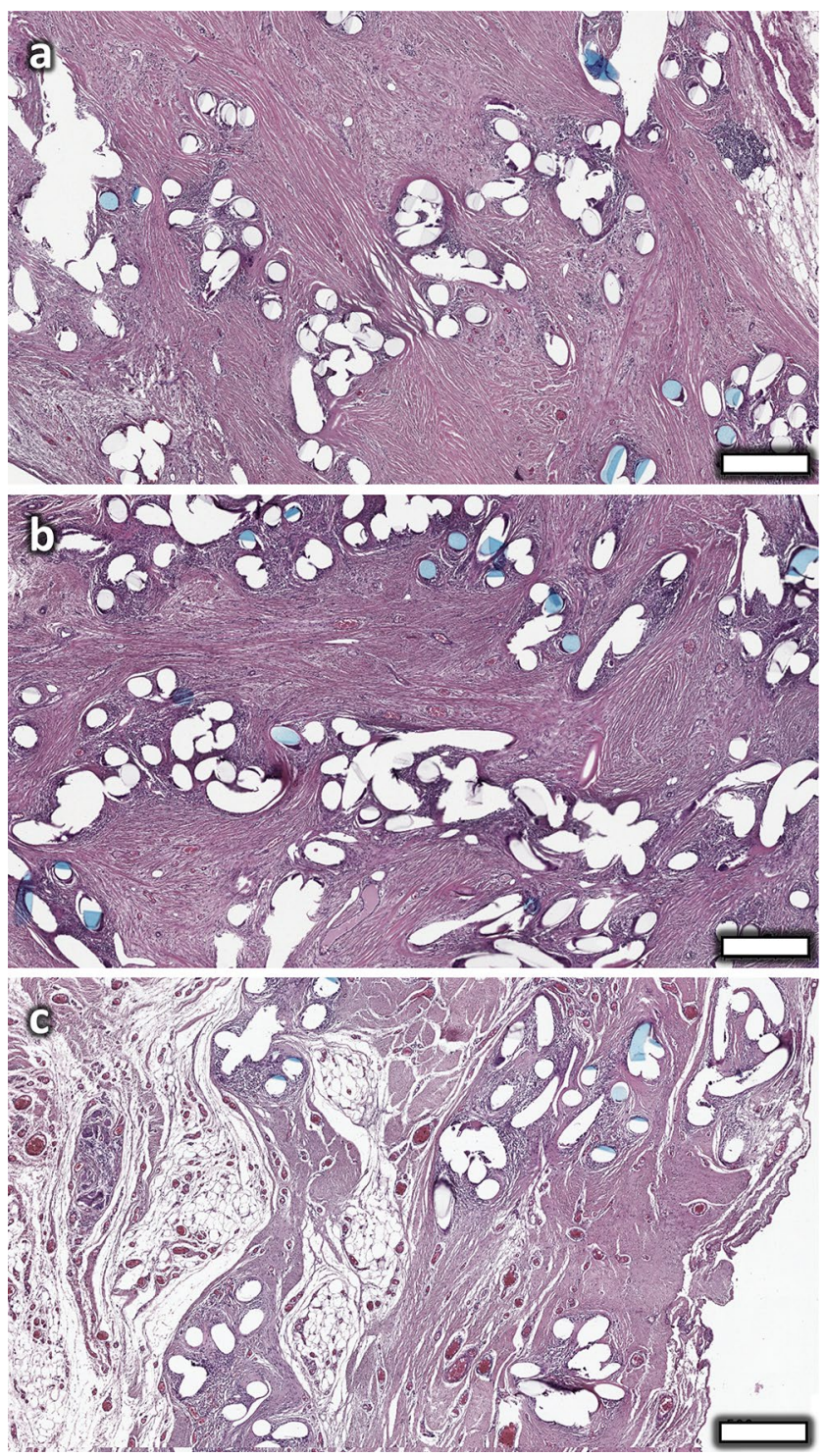

Fig. 1 HE stainings of three representative PP mesh samples with fibrosis. The mesh fibers are encapsulated by abundant fibrous tissue that bridges between adjacent mesh fiber bundles. Scale bar $=500 \mu \mathrm{m}$. Images of explants \#6 (a), \#7 (b), \#2 (c) with ImmPRESS ${ }^{\text {TM }}$ HRP (Peroxidase) Polymer Detection Kit (Vector Laboratories, US). TSA reagents were diluted with $1 \times$ Plus Amplification Diluent (PerkinElmer/Akoya Biosciences, US).

\section{Protocol}

Tissue sections were deparaffinized with xylene, rehydrated through graded alcohol and Milli-Q, before incubation in $3.5 \%$ formalin for $10 \mathrm{~min}$. Sections were then placed in a cuvette filled with Milli-Q and pH6 citrate buffer (1:10) and treated for $10 \mathrm{~min}$ at $110{ }^{\circ} \mathrm{C}$ in a Decloaking Chamber ${ }^{\mathrm{TM}}$ (Biocare Medical, US) for antigen retrieval. Afterwards, sections were washed with Milli-Q and TBST Tris (Buffered Saline with Tween 20, Dako) and cooled. Nonspecific binding was blocked by incubation with antibody diluent for $10 \mathrm{~min}$.

These steps were followed by incubation with the primary antibody of the first marker. After incubation, sections were rinsed in TBST Tris and incubated with the secondary antibody for $20 \mathrm{~min}$, before applying FITC-staining with the Opal ${ }^{\mathrm{TM}} 520$ Reagent Pack (1:100, PerkinElmer/Akoya Biosciences) for $10 \mathrm{~min}$. Sections were then washed with TBST Tris and placed in a cuvette filled with AR6 Buffer (PerkinElmer/Akoya Biosciences) and Milli-Q (1:10). For antibody stripping, the cuvette was microwave treated for 3 min at $385 \mathrm{~W}$ reaching a maximal temperature of $92{ }^{\circ} \mathrm{C}$ and $15 \mathrm{~min}$ at $120 \mathrm{~W}$ reaching a maximal temperature of $90{ }^{\circ} \mathrm{C}$, before being cooled with cold water. Sections were removed and rinsed with Milli-Q, before incubation with TBST Tris overnight.

The second marker was applied on the following day. After applying the primary and secondary antibodies of the second marker, sections were Cy5-stained with the TSATMPlus Cyanine 5 System (1:50, PerkinElmer/Akoya Biosciences). Sections were then rinsed in Milli-Q and finally counterstained and cover-slipped with VECTRASHIELD® HardSet $^{\mathrm{TM}}$ Antifade Mounting Medium with DAPI (Vector Laboratories).
Table 2 List of monoclonal antibodies sorted alphabetically

\begin{tabular}{lllll}
\hline Antibody & Clone & Dilution & Incubation time & Manufacturer \\
\hline CD68 & KP1 & $1: 6000$ & 30 min & Dako \\
CD163 & 5C6 FAT & $1: 800$ & Over night & BMA Biomedicals \\
CD206 & 15-2 & $1: 200$ & 30 min & Acris \\
Collagen-I & 5D8-G9 & $1: 125$ & Over night & ThermoFisher \\
Collagen-III & FH-7A & $1: 200$ & 30 min & ThermoFisher \\
MMP-2 & CA-4001 or & $1: 300$ & Over night & ThermoFisher \\
& CA719E3C & & & \\
MMP-8 & EP1232Y & $1: 300$ & Over night & abcam \\
\hline
\end{tabular}




\section{Analysis of fluorescence images/stainings}

Fluorescence imaging was performed with an Axio Imager 2 epifluorescence microscope (20x, Zeiss, Germany) and the TissueFAXS PLUS system (TissueGnostics, Austria). Images were processed and quantitatively analyzed with StrataQuest Analysis Software (v6, TissueGnostics). On average, 41 (range: 10-130) individual mesh fibers were manually outlined in each mesh sample and processed using the Euclidean distance to establish Euclidean distance maps with six regional zones (zone 1: 0-50 $\mu \mathrm{m}$, zone 2: 50-100 $\mu \mathrm{m}$, zone 3: 100-150 $\mu \mathrm{m}$, zone 4: 150-200 $\mu \mathrm{m}$, zone 5: 200-250 $\mu \mathrm{m}$, zone 6: 250-350 $\mu \mathrm{m}$ ) from the mesh fibers (Fig. 2). The Euclidean distance is a method commonly used in image processing that uses the Pythagorean formula to measure the distance between two pixels in a straight line. The detection of cells and positive marker signals was done as described previously [13]. Briefly, optimized DAPI images were used to detect and segment nuclei whose areas were used to measure the mean staining intensities for FITC- and Cy5-shades of the respective markers. Cells whose mean staining intensity was above 100 were considered "positive" and detection was verified with backward gating (Fig. 3). In addition, for collagen-I and -III the positive signal area (pixels with an intensity $>100$ ) was detected for each regional zone (Fig. 4). We recorded the total area of each zone, the total area of collagen, the total number of nuclei, as well as the percentages of FITC $^{+}$ $\left(\mathrm{CD}^{+} 8^{+}\right), \mathrm{Cy}^{+}\left(\right.$second marker $\left.^{+}\right)$, and double positive,
FITC $^{+} \mathrm{Cy}^{+}\left(\mathrm{CD}^{+} 8^{+}\right.$and second marker $\left.{ }^{+}\right)$, cells in each zone.

In addition, controls without primary antibody and controls with isotype antibodies were performed. The omission of the primary antibodies and substitution of the primary antibodies with the isotype antibodies at the same final concentrations resulted in lack of immunostaining.

\section{Statistical analysis}

Calculations were done with MATLAB® ${ }^{\circ .1}$ and Image Processing Toolbox 9.5 (The MathWorks, US). Statistical analysis was performed with Statistical Package for Social Sciences software (SPSS $®$ v23, IBM, US).

\section{Results}

\section{Distribution of cell densities and macrophages in relation to the distance from the mesh fibers}

Mesh-tissue complexes exhibited a typical highly localized foreign body reaction with inner inflammatory cell infiltrates and outer fibrotic collagen-containing capsules (Fig. 4). To determine the percentage of macrophages (as function of total cells) in each zone, we first studied cell densities, defined as cells per $\mathrm{mm}^{2}$. The cell density decreased with increasing distance from the mesh fibers from 4133 cells $/ \mathrm{mm}^{2}$ in zone $1(0-50 \mu \mathrm{m})$ to 1583 cells/

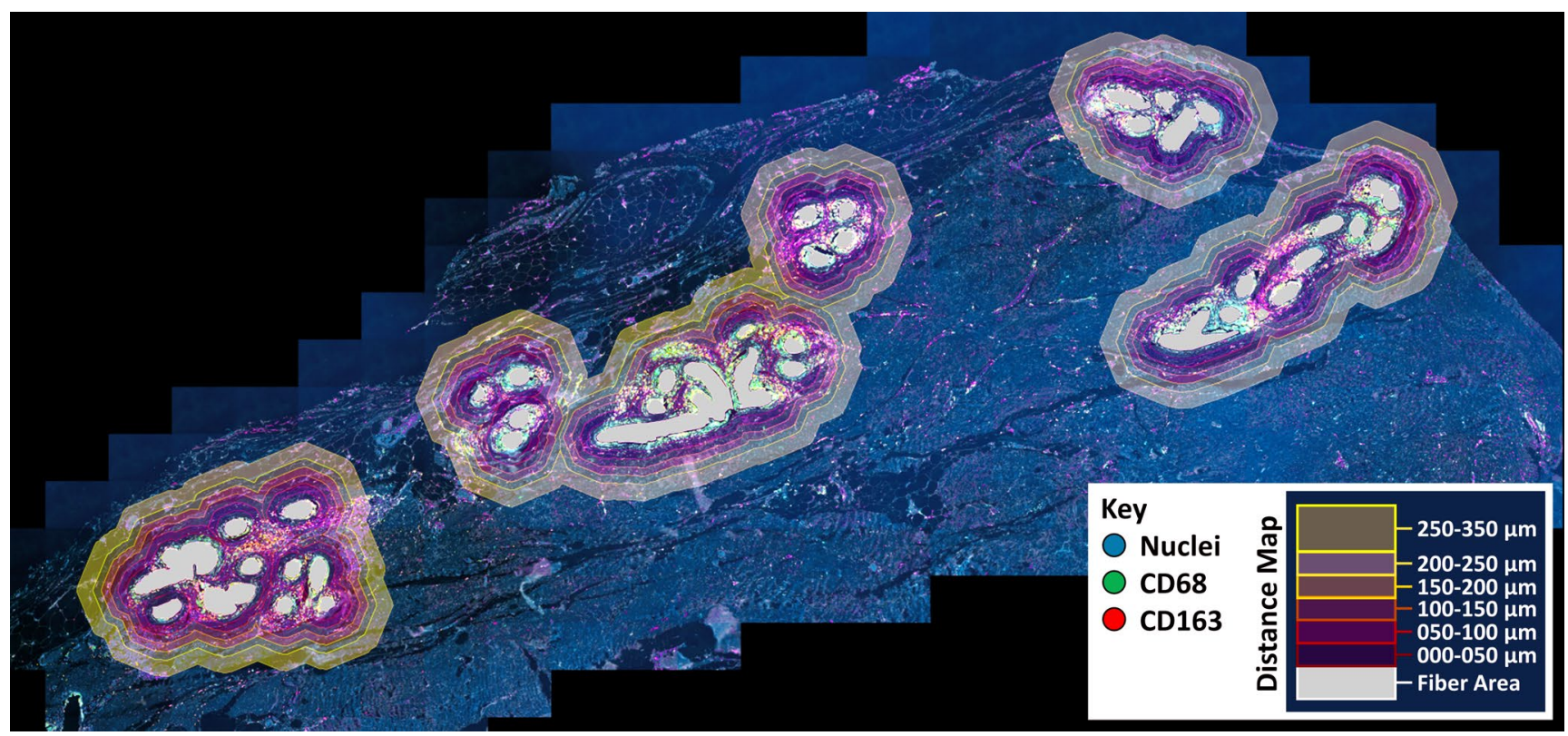

Fig. 2 Immunofluorescent labeling with distance map algorithm for spatial analysis of the host reaction to mesh implants. Tissue section of a human mesh explant with selected fiber areas in gray and the automatically generated Euclidean distance map. The distance map consists of six regional zones covering a total distance of $350 \mu \mathrm{m}$ from the mesh fibers. Image of explant \#3 


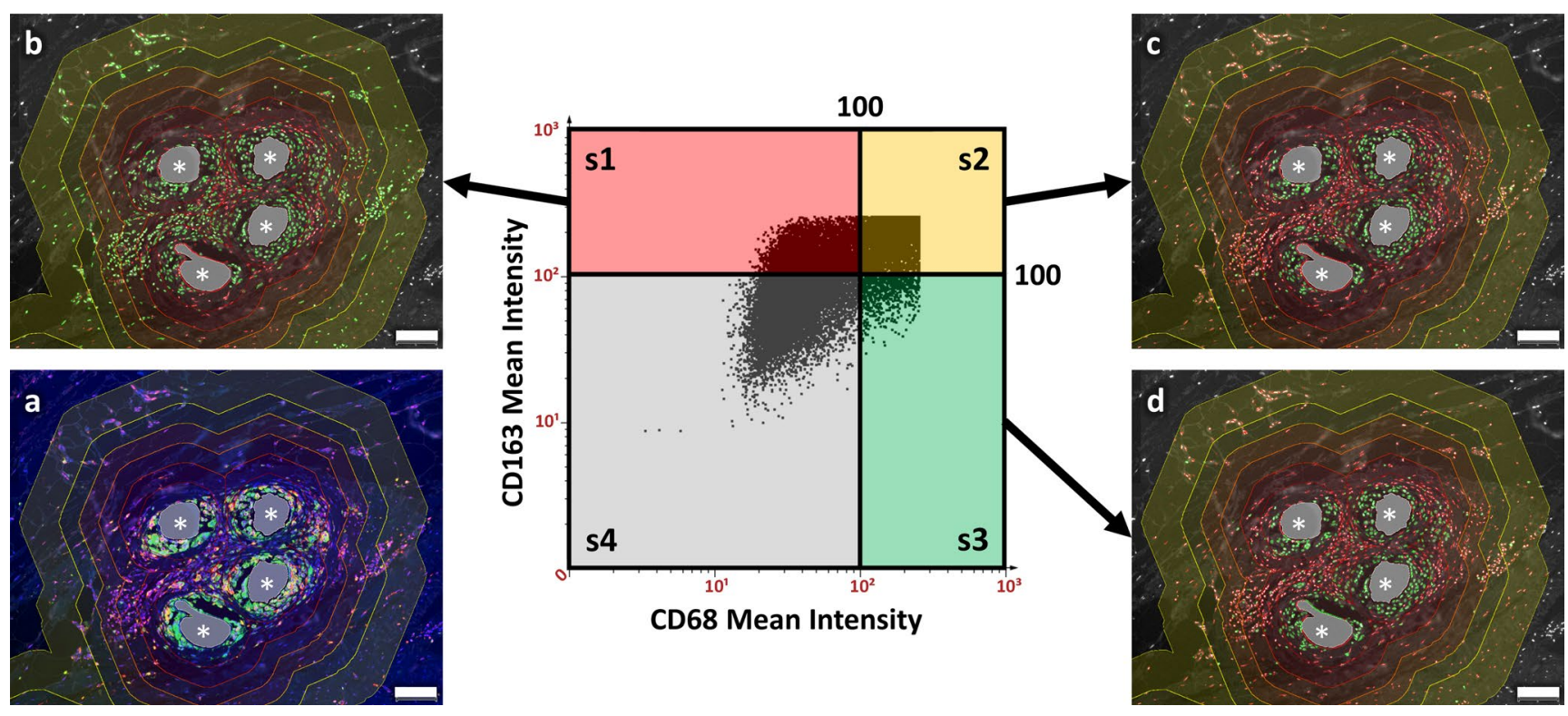

Fig. 3 Backward gating of macrophages participating in the foreign body reaction. a Immunofluorescent labeling of a human mesh explant for CD68 (green), CD163 (red), and nuclei with DAPI (blue). (s1-s4) Scatter plot of the mean cell intensities with CD68 on the $x$ axis and CD163 on the $y$ axis. Cells with a mean staining intensity $>100$ are considered to be "positive" and shown in green in the backward gating images (b-d). Backward gating of cells was done on DAPI grayscale images and compared with color images to verify detection. b Backward gating of $\mathrm{CD} 163^{+}$cells $(=\mathrm{s} 1$ and $\mathrm{s} 2)$. c Backward gating of $\mathrm{CD}^{+} 8^{+} \mathrm{CD}_{163}{ }^{+} \mathrm{M} 2$ macrophages (=s2). d Backward gating of $\mathrm{CD}^{+} 8^{+}$macrophages $(=\mathrm{s} 2$ and $\mathrm{s} 3)$. All images are superimposed with the regional zones of the Euclidean distance map that range from 0 to $50 \mu \mathrm{m}$ (dark red) to $250-350 \mu \mathrm{m}$ (bright yellow) in $50 \mu \mathrm{m}$ steps. Mesh fibers are marked with asterisks, scale bars $=100 \mu \mathrm{m}$. Images of explant \#3 (color figure online)

$\mathrm{mm}^{2}$ in zone6 $(250-350 \mu \mathrm{m})$. The number of $\mathrm{CD}^{+} 8^{+}$macrophages showed a similar decline, although the percentages decreased even more rapidly, from 41.7 to $7.5 \%$, respectively (Fig. 5; Table 3).

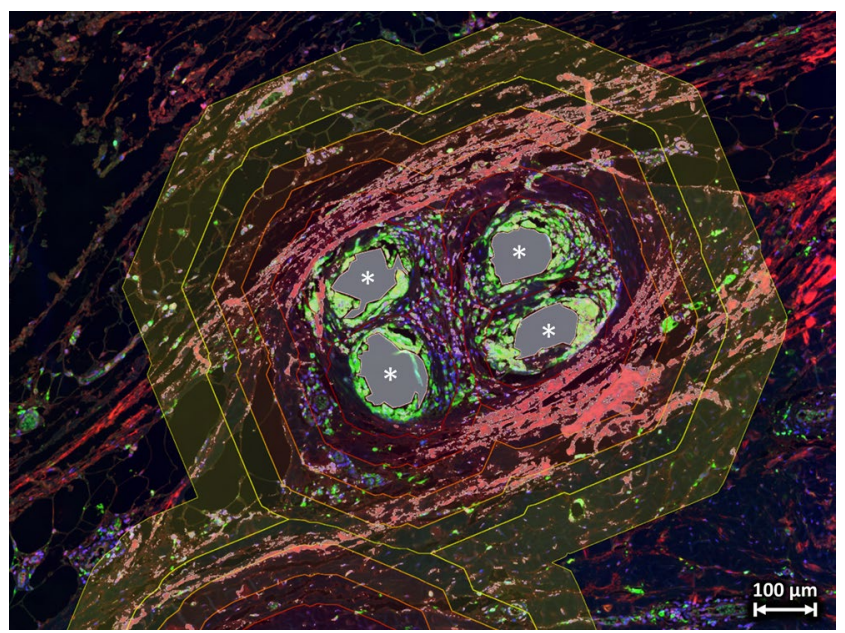

Fig. 4 Collagen detection in the vicinity of mesh fibers. Doublestained tissue section of a human mesh explant labeled for CD68 (green) and collagen-III (red) with superimposed fiber areas in gray and the regional zones of the Euclidean distance map $(0-50 \mu \mathrm{m}$ in dark red to $250-350 \mu \mathrm{m}$ in bright yellow). Detected collagen (pixel intensity $>100$ ) within the zones is highlighted with a gray shade and the number of pixels was counted to determine the total collagen area in each regional zone. Mesh fibers are marked with asterisks. Image of explant \#3 (color figure online)

\section{Spatial analysis of macrophage phenotypes}

Separate analysis for M1 $\left(\mathrm{CD} 68^{+} \mathrm{CD}^{+} 6^{+}\right)$and $\mathrm{M} 2$ phenotypes $\left(\mathrm{CD} 68^{+} \mathrm{CD} 163^{+}\right.$and $\left.\mathrm{CD} 68^{+} \mathrm{CD} 206^{+}\right)$revealed only few $\mathrm{M} 1$ macrophages with the highest percentage of $1.7 \%$ in zone1. In contrast, M2 macrophages were seen more frequently (Fig. 6; Table 3). As with the M1 macrophages, we observed the highest percentage of M2 macrophages in zone 1 with $18.3 \%$ and $23.1 \%$ for $\mathrm{CD}^{+} 8^{+} \mathrm{CD} 206^{+}$and $\mathrm{CD} 8^{+} \mathrm{CD} 163^{+}$, respectively. The relative proportions of M2 macrophages in relation to the total number of macrophages (e.g., $\mathrm{CD} 68^{+} \mathrm{CD} 163^{+} / \mathrm{CD} 68^{+}$) remained constant in each zone. The overall M2/M1 ratios were 28.8 and 39.6 for $\mathrm{CD} 68^{+} \mathrm{CD} 163^{+}$and $\mathrm{CD} 68^{+} \mathrm{CD} 206^{+}$, respectively, with similar zonal profiles of the ratios for both M2 marker combinations (Fig. 6). Collectively, these data demonstrate that these PP meshes presented a localized sustained M2 response. 
Fig. 5 Spatial distribution of cell densities and macrophages at the mesh-tissue interface. Dots correspond to the mean cell densities (cells per $\mathrm{mm}^{2}$ ) of all cells and macrophages $\left(\mathrm{CD}^{+} 8^{+}\right.$) in each regional zone, e.g., 0-50 $\mu \mathrm{m}$. Statistical significance between neighboring zones were determined with Welch-ANOVA followed by Dunnett's T3 post hoc test (*** $p<0.001, * * p<0.01$, ${ }^{*} p<0.05, \mathrm{NS} .=$ not significant $)$. The gray- and green-shaded areas mark the $95 \%$ confidence interval of the respective mean values for macrophages and all cells (blue lines). $N=7$ meshes each 7-9 stains (color figure online)

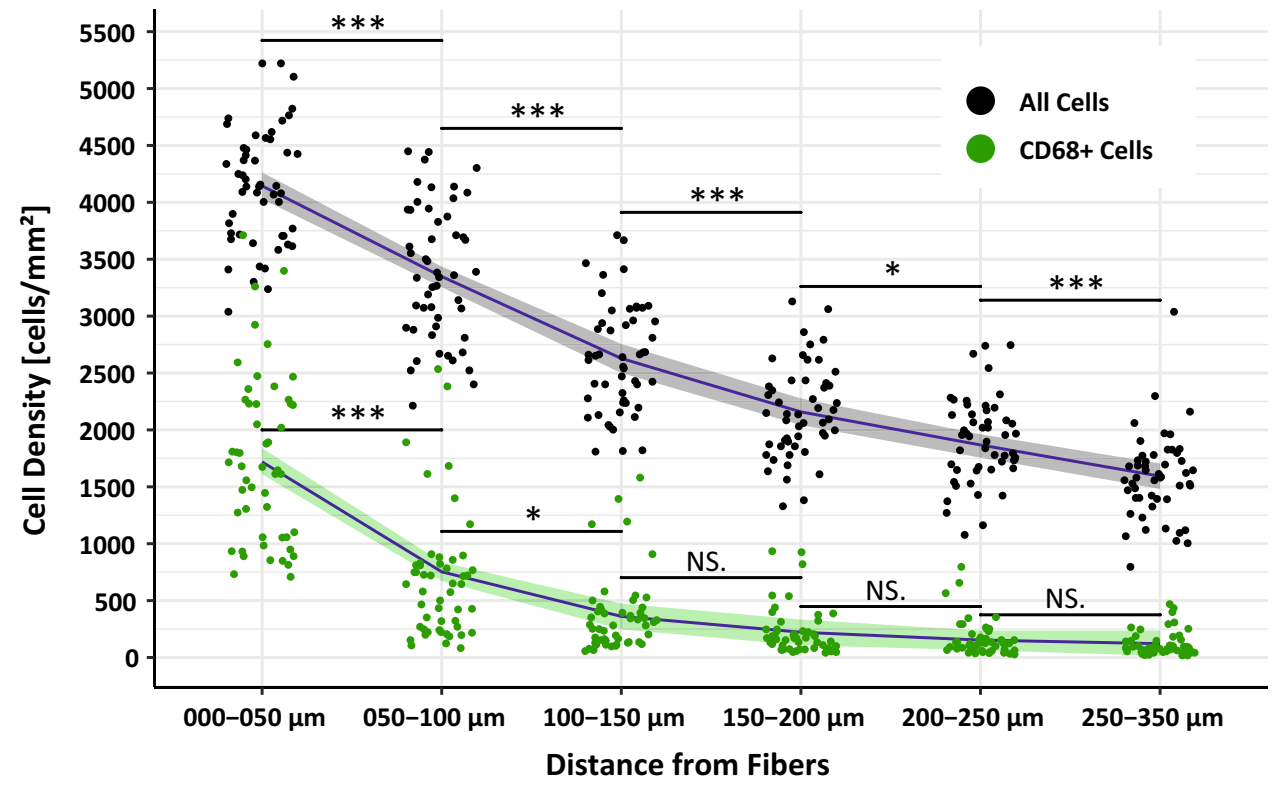

Table 3 Spatial analysis of cell densities, macrophages, and M2/M1 ratios

\begin{tabular}{|c|c|c|c|c|c|c|}
\hline \multirow{2}{*}{$\begin{array}{l}\text { Parameter ( } n=7 \text { PP } \\
\text { meshes) }\end{array}$} & \multicolumn{6}{|c|}{ Distance from Fibers } \\
\hline & $\begin{array}{l}\text { Zone1 } \\
000-050 \mu \mathrm{m}\end{array}$ & $\begin{array}{l}\text { Zone2 } \\
050-100 \mu \mathrm{m}\end{array}$ & $\begin{array}{l}\text { Zone3 } \\
100-150 \mu \mathrm{m}\end{array}$ & $\begin{array}{l}\text { Zone4 } \\
150-200 \mu \mathrm{m}\end{array}$ & $\begin{array}{l}\text { Zone5 } \\
200-250 \mu \mathrm{m}\end{array}$ & $\begin{array}{l}\text { Zone6 } \\
250-350 \mu \mathrm{m}\end{array}$ \\
\hline $\begin{array}{l}\text { Cell density (cells/ } \\
\mathrm{mm}^{2} \text { ) }\end{array}$ & $4133.8(40.2)$ & $3387.1(82.9)$ & $2628.3(66.9)$ & $2158.4(56.5)$ & $1904.8(52.0)$ & $1583.6(52.0)$ \\
\hline$\% \mathrm{CD} 8^{+}$cells & $41.7(2.3)$ & $19.7(2.1)$ & $13.6(1.6)$ & $10.3(1.3)$ & $8.5(1.1)$ & $7.5(0.9)$ \\
\hline$\% \mathrm{CD} 6^{+}$cells & $2.9(1.2)$ & $2.2(0.8)$ & $2.2(0.7)$ & $2.6(0.9)$ & $2.6(0.9)$ & $2.6(0.9)$ \\
\hline $\begin{array}{c}\% \mathrm{CD}^{2} 8^{+} \mathrm{CD} 86^{+} \\
\text {cells }(=\mathrm{M} 1)\end{array}$ & $1.7(0.6)$ & $0.4(0.1)$ & $0.3(0.1)$ & $0.4(0.1)$ & $0.2(0.1)$ & $0.3(0.1)$ \\
\hline $\begin{array}{l}\%{\mathrm{CD} 68^{+} \mathrm{CD}^{2} 6^{+} /}_{\mathrm{CD} 68^{+}}\end{array}$ & $6.5(2.6)$ & $4.1(1.7)$ & $3.8(1.4)$ & $6.4(2.0)$ & $4.5(1.4)$ & $8.8(3.8)$ \\
\hline$\% \mathrm{CD} 163^{+}$cells & $41.1(6.1)$ & $33.6(5.5)$ & $29.8(5.1)$ & $27.5(4.8)$ & $28.7(4.8)$ & $28.1(5.0)$ \\
\hline $\begin{array}{c}\% \mathrm{CD}^{+} 8^{+} \mathrm{CD} 163^{+} \\
\text {cells }(=\mathrm{M} 2[1])\end{array}$ & $23.1(3.6)$ & $10.2(1.9)$ & $6.8(1.2)$ & $4.7(0.8)$ & $4.2(0.7)$ & $3.2(0.4)$ \\
\hline $\begin{array}{l}\% \mathrm{CD} 68^{+} \mathrm{CD}_{163^{+}} / \\
\mathrm{CD}^{+} 8^{+}\end{array}$ & $58.6(9.2)$ & $65.2(7.4)$ & $66.5(6.1)$ & $66.8(6.3)$ & $71.3(6.4)$ & $73.3(7.2)$ \\
\hline$\% \mathrm{CD} 206^{+}$cells & $22.3(1.9)$ & $10.7(2.3)$ & $8.5(1.8)$ & $7.5(1.3)$ & $6.9(1.2)$ & $6.1(1.2)$ \\
\hline $\begin{array}{c}\% \mathrm{CD}^{+} 8^{+} \mathrm{CD} 206^{+} \\
\text {cells }(=\mathrm{M} 2[2])\end{array}$ & $18.3(1.3)$ & $6.5(1.6)$ & $4.5(1.1)$ & $3.4(0.8)$ & $3.1(0.7)$ & $2.6(0.6)$ \\
\hline $\begin{array}{l}\% \mathrm{CD} 68^{+} \mathrm{CD} 206^{+} / \\
\mathrm{CD}^{+} 8^{+}\end{array}$ & $57.2(3.8)$ & $52.9(4.2)$ & $57.6(4.9)$ & $59.5(5.8)$ & $63.8(6.7)$ & $60.6(7.3)$ \\
\hline $\mathrm{M} 2[1] / \mathrm{M} 1$ ratio & $42.4(20.1)$ & $45.7(17.3)$ & $67.3(31.0)$ & $20.5(7.3)$ & $29.1(8.4)$ & $12.5(4.4)$ \\
\hline M2[2]/M1 ratio & $57.9(34.7)$ & $38.3(15.8)$ & $70.8(46.4)$ & $24.8(14.6)$ & $23.5(8.1)$ & $11.0(5.1)$ \\
\hline
\end{tabular}

The cell density is defined as the average number of cells per $\mathrm{mm}^{2}$. Percentages of single-positive (e.g., CD68 ${ }^{+}$) and double-positive (e.g., $\mathrm{CD} 8^{+} \mathrm{CD} 86^{+}$) cells in relation to all cells and the proportions of double-positive cells with respect to the total number of macrophages (e.g., $\left.\mathrm{CD} 68^{+} \mathrm{CD} 163^{+} / \mathrm{CD}^{+} 8^{+}\right)$in each regional zone. M2/M1 ratios are given for both M2 marker combinations with the designations M2[1] and M2[2]. The data are presented as mean (SE)

\section{Collagen deposition and co-localization with macrophages}

To investigate collagen deposition, we determined the area of collagen-I and -III as well as its co-localization with cells and macrophages (Figs. 7, 8) in each regional zone. For collagen-I, the percentage area (based on the total area) was highest in zone1 with about $11 \%$, while it was relatively 
Fig. 6 Characterization of the macrophage response to human polypropylene mesh explants. The green bars represent the mean percentages of macrophages $\left(\mathrm{CD}^{+} 8^{+}\right)$, yellow and orange of $\mathrm{M} 2$ macrophages (e.g., $\mathrm{CD}^{+} 8^{+} \mathrm{CD} 163^{+}$), and blue of M1 macrophages $\left(\mathrm{CD}^{+} 8^{+} \mathrm{CD} 6^{+}\right)$in each regional zone. The respective M2/M1 ratios are indicated with the yellow triangles $\left(\mathrm{CD} 68^{+} \mathrm{CD} 63^{+}\right.$/ $\mathrm{CD}^{+} 8^{+} \mathrm{CD}^{+} 6^{+}$) and orange squares $\left(\mathrm{CD}^{+} 8^{+} \mathrm{CD} 206^{+} /\right.$ $\left.\mathrm{CD} 68^{+} \mathrm{CD} 86^{+}\right)$. The percentage scale for the macrophages is on the left and for the M2/M1 ratios on the right. Whiskers mark the SEs ( $n=7$ meshes) (color figure online)

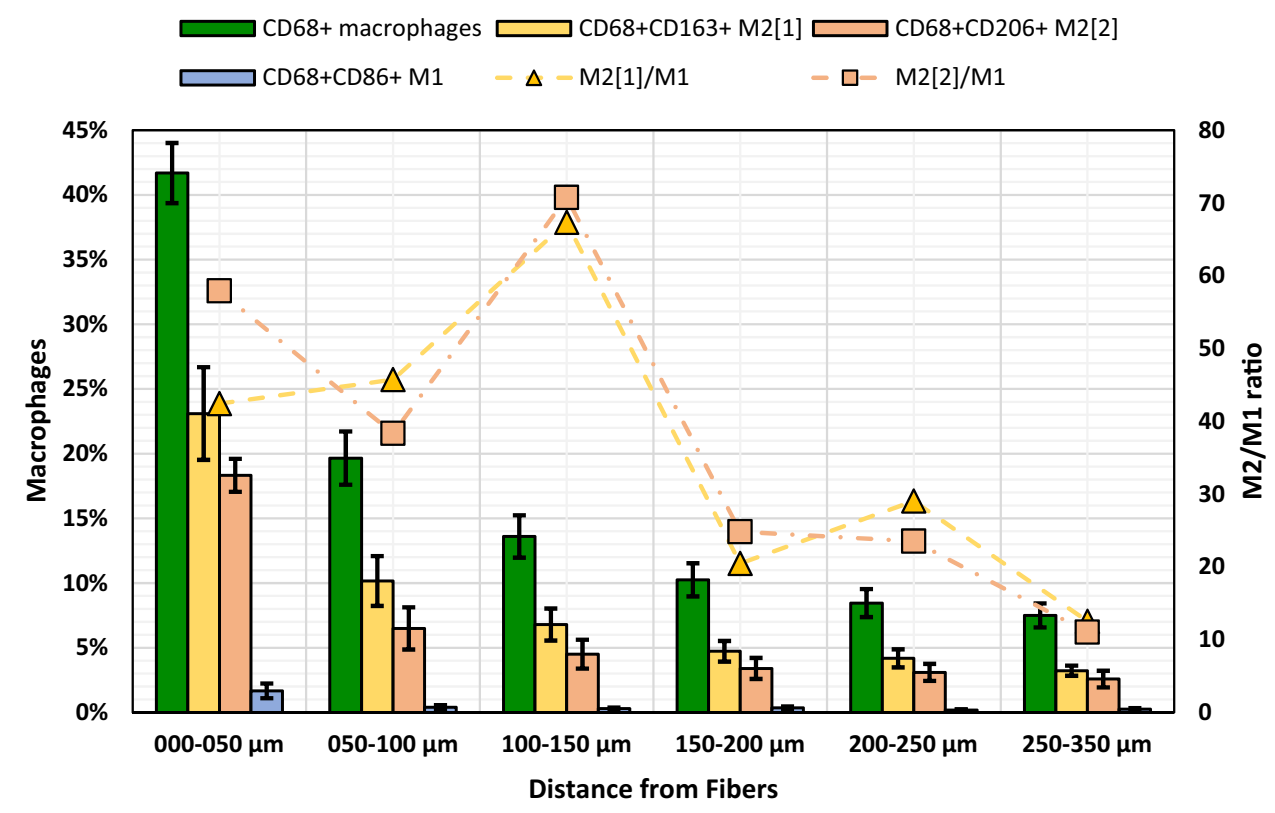

constant in the other zones with about $6.5 \%$. In contrast, the percentage area of collagen-III increased steadily from about $7.5 \%$ in zone 1 to about $10.2 \%$ in zone4 (150-200 $\mu \mathrm{m})$ and remained constant in the two most distant zones (Table 4; Fig. 9). By relating the collagen areas in each regional zone to the respective number of all cells, we found that the average collagen area per cell for both collagens increased with increasing distance from the mesh fibers (Fig. 10). Furthermore, both collagens showed considerable co-localization with $\mathrm{CD}^{+}{ }^{+}$cells, highest for collagen-I in zone1 $(28.1 \%)$, and for collagen-III in zone5 $(200-250 \mu \mathrm{m})$ and zone6 (250-350 $\mu \mathrm{m})$. Overall, about $50 \%$ of macrophages colocalized with collagen-I and about $28 \%$ with collagen-III.

\section{Distribution of MMP-2 and MMP-8 and co-expression with macrophages}

Spatial analysis of matrix metalloproteinases revealed only little MMP-8 expression (Fig. 11) but considerable expression of MMP-2 (Fig. 12), almost equally distributed in all zones. Overall, about $55 \%$ of the macrophages co-expressed MMP-2 in each zone (Table 5).

\section{Discussion}

The examination of the spatial morphology of the macrophages at the foreign body granuloma around meshes by combining a custom Euclidean distance map algorithm with immunofluorescence staining of entire tissue sections of polypropylene (PP) mesh explants demonstrated that cell density and macrophage ratio decreased with distance to the PP fibers, and that these were predominantly M2 macrophages. In addition, more than $70 \%$ of the macrophages showed co-expression with collagen-I or -III and more than 50\% with MMP-2, which demonstrates these cells are important participants in mesh-tissue remodeling.

When examined, the cell densities and the percentages of macrophages decreased with increasing distance from the mesh fibers. Interestingly, the proportion of M2 macrophages in relation to the total number of macrophages was not significantly different between regional zones, highlighting the consistent M2 environment. The highest percentages of both M1 and M2 macrophages in situ were observed within the first $50 \mu \mathrm{m}$ from the mesh surface, which is in agreement with other studies on PP meshes $[8,11,14]$. On the contrary to our findings, several animal studies on PP meshes have shown mainly M1 macrophages to surround the mesh fibers [7, 8, 11]. The predominance of M1 macrophages was confirmed by Nolfi et al. at human PP mesh explants from the pelvic floor, which were explanted due to mesh exposure and chronic pain [9]. Any quantification strongly depends on marker, cutoff, the distance to the mesh fibers, and the location of the investigated region, however the difference we record here is striking ('M1' $\approx 6 \%$ vs ' $\mathrm{M} 2$ ' $\approx 60 \%$ ). The mesh placement at the pelvic floor may favor proinflammatory morphology of macrophages, whereas locations within the abdominal wall tends to show less inflammation [9, 15]. In addition, the medical reason for mesh removal may be decisive for macrophage morphology. Our explants represent the chronic foreign body reaction, but they have not been removed because of acute clinically apparent inflammation or erosion. Finally, M1/M2 morphology in humans may differ to the results in animals, especially considering many of these markers are not shared and that meshes are 

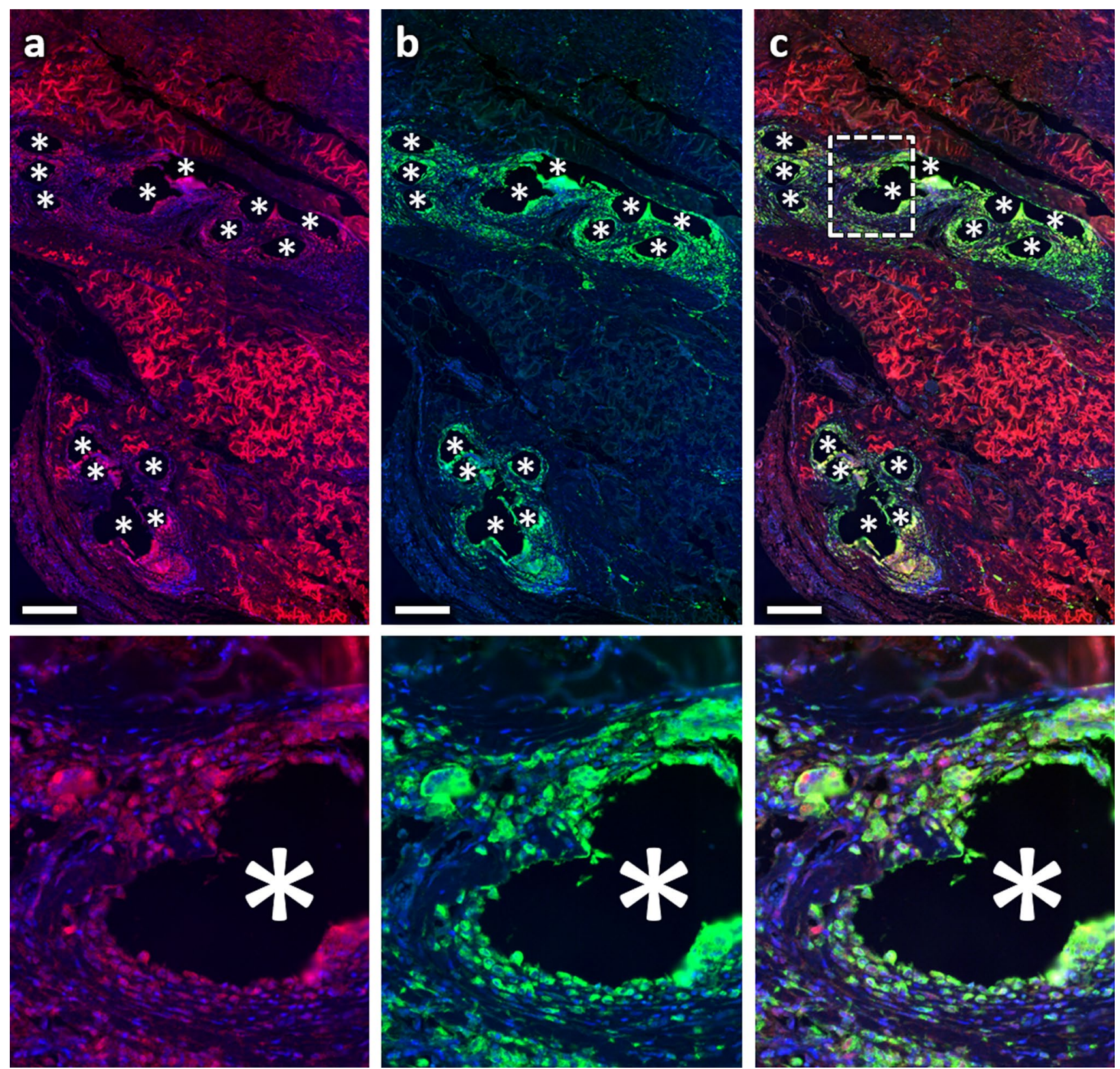

Fig. 7 Immunofluorescence labeling of macrophages (CD68) and collagen-I. a Labeling of collagen-I (Cy5, red), b CD68 (FITC, green), and $\mathbf{c}$ overlay. Nuclei are labeled with DAPI (blue). Images corresponding to the dashed rectangular ROI are given below, respectively. Locations of mesh fibers are marked with asterisks, scale bar $=200 \mu \mathrm{m}$. Images of explant \#3 (color figure online) not adapted to the physiology of animals but rather to that of humans.

The M2 response observed in this study was accompanied by abundant collagen deposition, leading to fibrosis. This is in agreement with several studies on fibrotic pathogenesis like pulmonary fibrosis or hepatic fibrosis [12, 16-19]. Most collagen-I was found directly at the interface to the meshes where the cell density and percentage of M2 macrophages was highest, while in the more distant zones there was more collagen-III, but significantly less M2 macrophages. These observations are consistent with the knowledge that profibrotic M2 macrophages produce various mediators that directly activate fibroblasts known to be mainly located in the outer fibrotic capsule, which in turn control ECM deposition [19]. The observed co-localization of macrophages with collagen-I, especially directly at the mesh-tissue interface (>50\%), could indicate that M2 macrophages are responsible for collagen-I degradation via a mannose receptormediated (CD206) pathway after MMP cleavage, as discovered by Madsen et al. [20]. Alternatively or additionally, 

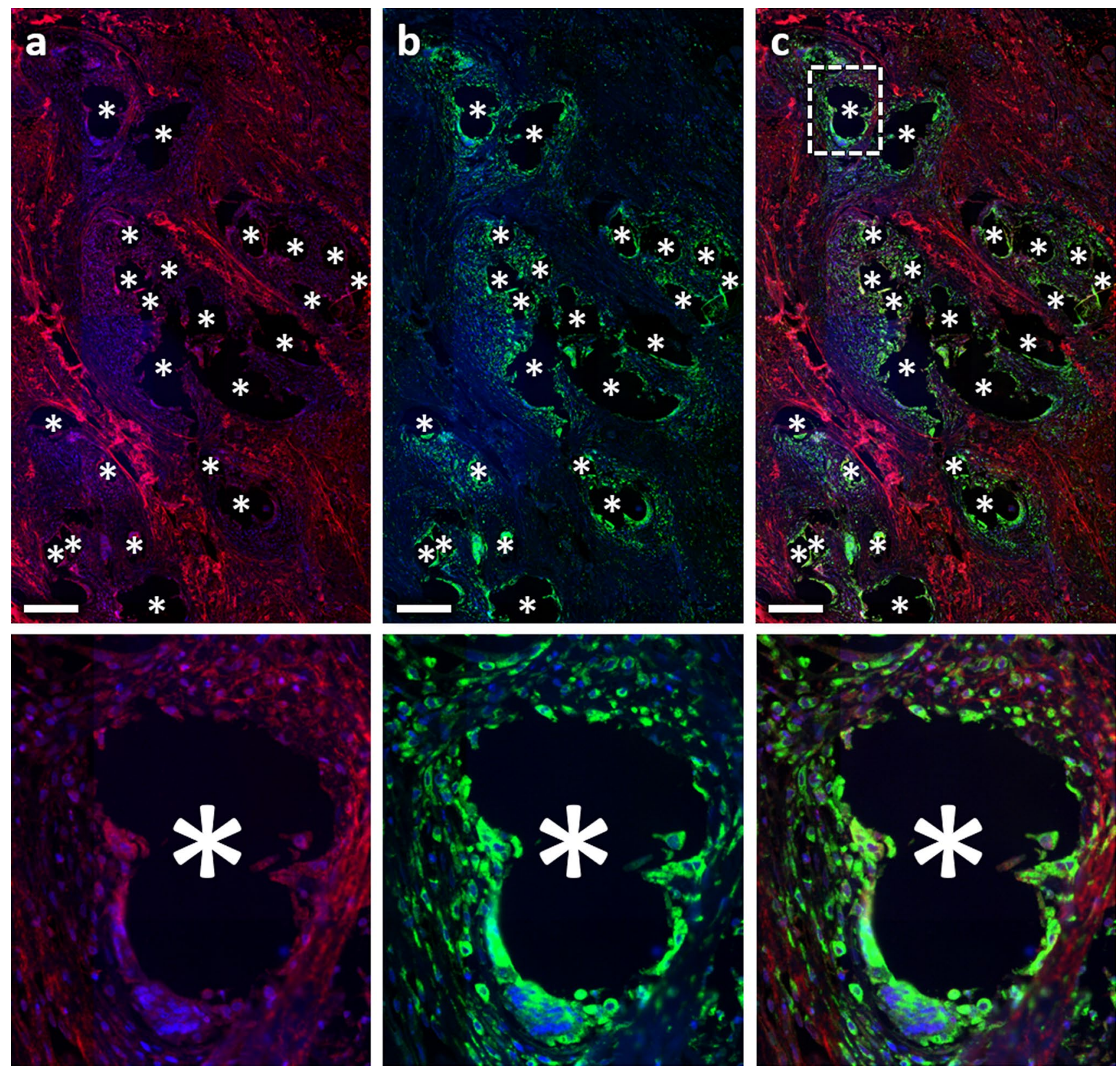

Fig. 8 Immunofluorescence labeling of macrophages (CD68) and collagen-III. a Labeling of collagen-III (Cy5, red), b CD68 (FITC, green), and $\mathbf{c}$ overlay. Nuclei are labeled with DAPI (blue). Images corresponding to the dashed rectangular ROI are given below, respectively. Locations of mesh fibers are marked with asterisks, scale bar $=200 \mu \mathrm{m}$. Images of explant \#7 (color figure online) macrophages may be involved in the synthesis of collagen-I, since the synthesis of other collagen types has been demonstrated in animals and humans [21, 22].

Profibrotic M2 macrophages are also known to produce their own MMPs, which regulate inflammatory cell recruitment and ECM turnover [19]. MMP-8 was rarely observed, whereas abundant MMP-2 expression was present in all regional zones, which is consistent with previous studies that reported an up-regulated MMP-2 protein synthesis and enzymatic activity following mesh implantation [9, 23, 24].
About half of the macrophages were found to produce MMP2. MMP-2 is a gelatinase that degrades collagens, its production by macrophages here may be an attempt to remodel the foreign body. However, the side effects may cause instability of the granuloma, as observed in atherosclerotic plaque rupture [25], and likely inhibit normal scar formation and maintain persistent cell turnover. Future studies will have to verify functionality of MMPs, e.g., by ELISA, zymography techniques, or RT-PCR gene expression, although the overall proteinase activity is altered by tissue inhibitors of 
Table 4 Spatial distributions of collagen-I and collagen-III as well as co-localization with cells and macrophages

\begin{tabular}{|c|c|c|c|c|c|c|}
\hline \multirow{2}{*}{$\begin{array}{l}\text { Parameter ( } n=7 \mathrm{PP} \\
\text { meshes) }\end{array}$} & \multicolumn{6}{|c|}{ Distance from Fibers } \\
\hline & $\begin{array}{l}\text { Zone1 } \\
000-050 \mu \mathrm{m}\end{array}$ & $\begin{array}{l}\text { Zone2 } \\
050-100 \mu \mathrm{m}\end{array}$ & $\begin{array}{l}\text { Zone3 } \\
\text { 100-150 } \mu \mathrm{m}\end{array}$ & $\begin{array}{l}\text { Zone4 } \\
150-200 \mu \mathrm{m}\end{array}$ & $\begin{array}{l}\text { Zone5 } \\
\text { 200-250 } \mu \mathrm{m}\end{array}$ & $\begin{array}{l}\text { Zone6 } \\
250-350 \mu \mathrm{m}\end{array}$ \\
\hline$\%$ Col- $\mathrm{I}^{+}$area & $11.1(2.1)$ & $6.7(1.2)$ & $6.7(1.1)$ & $6.9(1.3)$ & $6.5(1.1)$ & $6.1(0.6)$ \\
\hline$\%{\mathrm{Col}-\mathrm{III}^{+}}$area & $7.5(0.9)$ & $8.2(0.8)$ & $9.3(0.9)$ & $10.2(1.0)$ & $10.3(1.6)$ & $10.2(1.8)$ \\
\hline 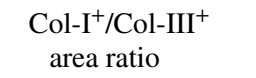 & $1.4(0.2)$ & $0.9(0.2)$ & $0.9(0.3)$ & $0.8(0.3)$ & $0.8(0.3)$ & $0.7(0.1)$ \\
\hline$\%$ Col-I $^{+}$cells & $28.1(5.8)$ & $16.7(4.0)$ & $14.9(2.6)$ & $14.8(2.3)$ & $15.9(1.7)$ & $17.8(1.3)$ \\
\hline $\begin{array}{l}\%{\mathrm{CD} 68^{+} \mathrm{Col}-\mathrm{I}^{+}}^{\text {cells }}\end{array}$ & $19.1(4.3)$ & $6.7(2.3)$ & $4.2(1.3)$ & $2.7(0.8)$ & $2.3(0.8)$ & $2.3(0.5)$ \\
\hline $\begin{array}{l}\text { \% } \mathrm{CD}^{2} 8^{+} \mathrm{Col}-\mathrm{I}^{+} / \\
\mathrm{CD}^{+} 8^{+}\end{array}$ & $52.2(8.4)$ & $46.3(8.6)$ & $46.7(8.8)$ & $42.3(9.1)$ & $40.4(7.5)$ & $44.4(7.2)$ \\
\hline$\% \mathrm{Col}-\mathrm{III}^{+}$cells & $17.7(2.7)$ & $15.1(2.2)$ & $16.4(1.9)$ & $18.6(1.9)$ & $20.2(2.8)$ & $22.5(2.5)$ \\
\hline $\begin{array}{l}\% \mathrm{CD}^{2} 8^{+} \mathrm{Col}-\mathrm{III}^{+} \\
\text {cells }\end{array}$ & $10.2(2.3)$ & $3.0(0.8)$ & $2.3(0.5)$ & $1.6(0.2)$ & $1.2(0.2)$ & $1.5(0.2)$ \\
\hline $\begin{array}{l}\%{\mathrm{CD} 68^{+} \mathrm{Col}-\mathrm{III}{ }^{+} /}^{\mathrm{CD}^{2} 8^{+}}\end{array}$ & $29.3(5.4)$ & $22.5(3.2)$ & $28.4(2.7)$ & $30.7(1.1)$ & $29.1(2.2)$ & $36.5(2.3)$ \\
\hline
\end{tabular}

Percentage areas of collagen-I and -III (e.g., Col- $\mathrm{I}^{+}$area) as function of the total area of each regional zone with corresponding collagen ratios. Percentages of cells (e.g., Col- ${ }^{+}$cells) and macrophages (e.g., $\mathrm{CD}^{+} 8^{+} \mathrm{Col}-\mathrm{I}^{+}$cells) co-localizing with collagen-I and -III, and the proportions of co-localizing macrophages relative to the total number of macrophages (e.g., $\mathrm{CD} 68^{+} \mathrm{Col}-\mathrm{I}^{+} / \mathrm{CD} 68^{+}$) in each regional zone. The data are presented as mean (SE)

Fig. 9 Spatial analysis of collagen-I and -III deposition. Bars represent the average percentage areas of collagen-I (blue) and collagen-III (green) in relation to the total area of the corresponding regional zones. Whiskers mark the SEs. No statistically significant differences were found between any zones ( $n=7$ meshes) (color figure online)

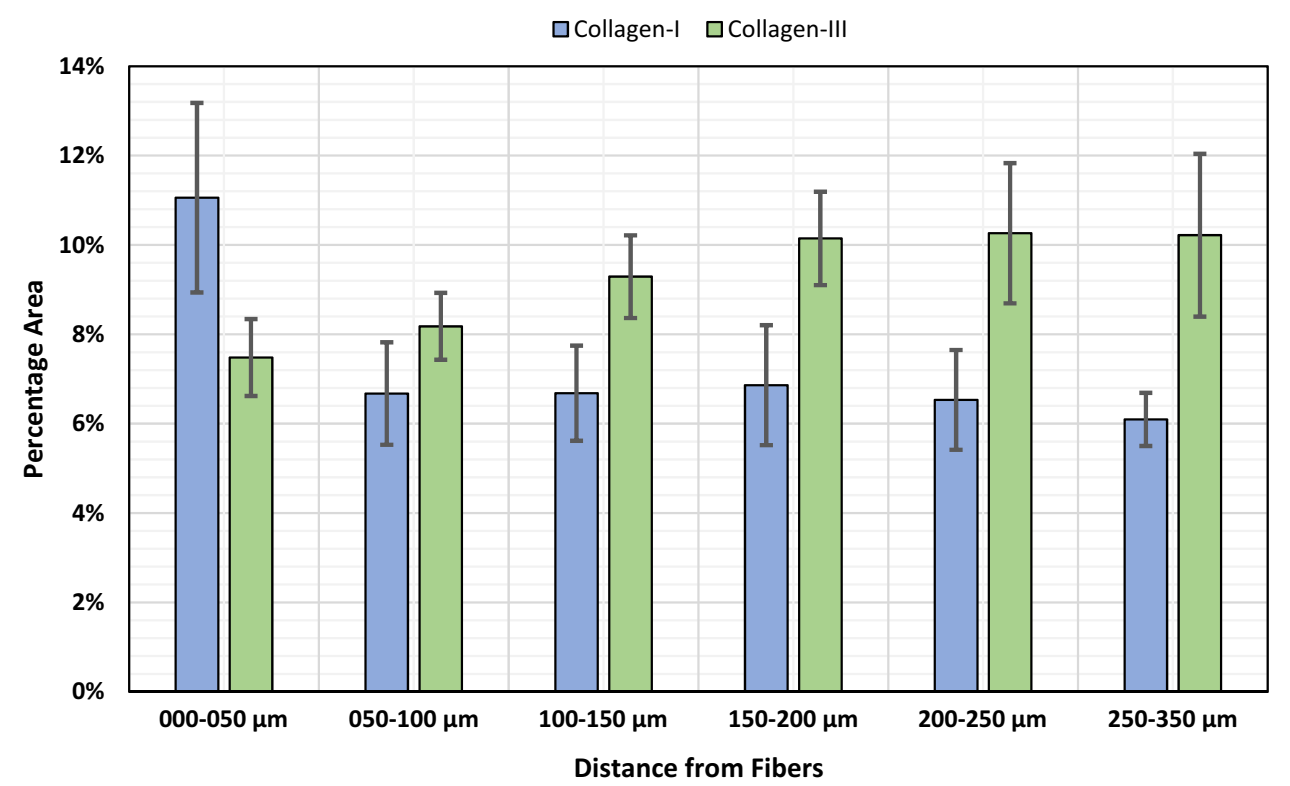

metalloproteinases (TIMPs), as well, but in this study, we just aimed to demonstrate the local expression without going into the functionality discourse.

Several limitations of our study have to be considered. Our collection of explanted meshes represents a selection from patients who apparently had a recurrence of an abdominal wall hernia with different intervals after implantation in nonhealthy tissues. Furthermore, only a limited sample size was available, covering three different mesh types with different textile properties (e.g., textile structures, pore sizes). In addition to the many confounders given by the complex staining protocol, it is the location and size of the investigated region that affect the results. Therefore, we used a Euclidean distance map algorithm that created six regional zones adjacent to the mesh fibers. This allowed us to spatially quantify cells and collagen deposits. Our choice of six regional zones, which covered $350 \mu \mathrm{m}$ from the mesh interface ensured that most 
Fig. 10 Regional distribution of collagen-I and -III per cell. Box plot with Tukey whiskers represents the average collagenI (blue) and -III (green) area per cell in each regional zone $(n=7$ meshes) (color figure online)

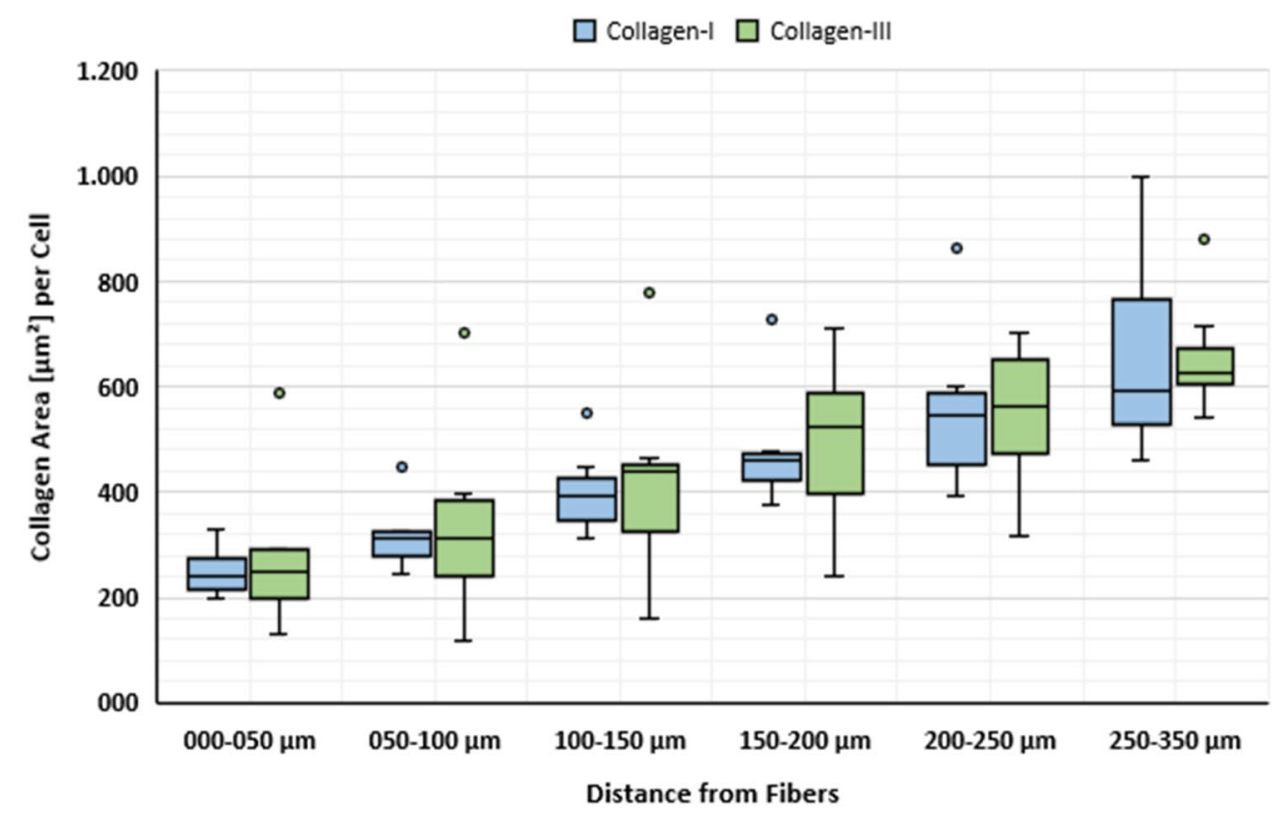

of the inflammatory infiltrate around each mesh fiber was included. By relating the total number of cells or positive signal area to the total area of the regional zone, we were able to create a robust, normalized measurement. For cells, the analysis of the staining intensity only in the area of the nuclei cannot exclude positive staining based on some overlapping cytoplasm membrane, but the probability is considerably reduced by sectioning at a thickness of about $2 \mu \mathrm{m}$. In addition, we applied a cutoff value of 100 for the mean staining intensity of cells, as described [13]. This allowed us to determine positive cells in an objective and reliable way and provided us with the most confidence for true positive detection.

In addition, as mentioned, macrophage polarization nomenclature is under scrutiny because of overlapping markers and the broad spectrum of macrophage origin and functional distinctions in tissues [26]. Hence, even though CD86 is considered an M1-specific marker, it can be identified in the M2 macrophage subset: M2b. Therefore, although we label these cells M1 for simplicity, the reality is more complex, and these could also be M2b or other macrophages in the multidimensional spectrum of polarization. Regardless of nomenclature, our findings do not implicate M1 or M2b cells as major components of the mesh implants we examined. In addition, even though we report on two M2 macrophage groups $\left(\mathrm{CD} 163^{+}\right.$or $\mathrm{CD} 206^{+}$), we acknowledge that these may indicate the same cells, as M2a and M2c cells can express both markers [27], while tumor macrophage studies show approximately half of CD206 ${ }^{+}$macrophages expressed CD163 [28]. Although it may be useful to fully categorize these cells with MALDI proteomics approaches for example, this was beyond the scope of our study - which aimed to address which broad category of macrophage (inflamed or wound healing) was related to collagen deposition at the foreign body granuloma.

In conclusion, the findings of the present study suggest that the foreign body reaction to PP meshes is associated with an M2 response that persists even years after implantation and is related to collagen deposition and turnover. Therefore, our findings challenge the idea that a stimulated transformation of macrophages towards the M2 phenotype is a solution to ameliorate the long-term foreign body reaction $[11,14,29]$. Future studies are required to assess whether these M2 macrophages are responsible for excessive fibrosis with all its clinical side effects, and whether attenuating this response is able to reduce complications after abdominal wall hernia repair. 

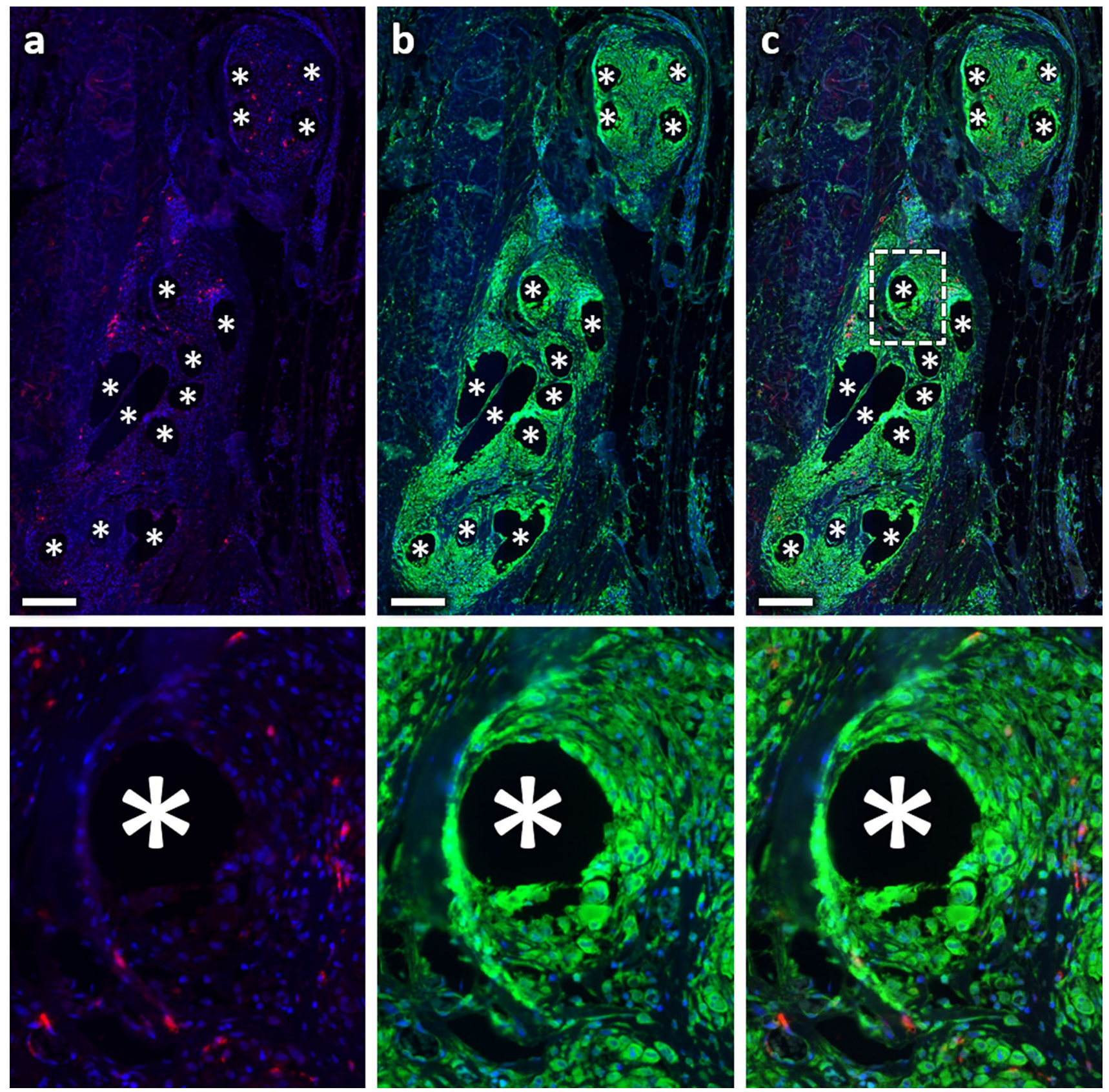

Fig. 11 Immunofluorescence labeling of macrophages (CD68) and MMP-8. a Labeling of MMP-8 (Cy5, red), b CD68 (FITC, green), and $\mathbf{c}$ overlay. Nuclei are labeled with DAPI (blue). Images cor- responding to the dashed rectangular ROI are given below, respectively. Locations of mesh fibers are marked with asterisks, scale $\mathrm{bar}=200 \mu \mathrm{m}$. Images from explant \#3 (color figure online) 

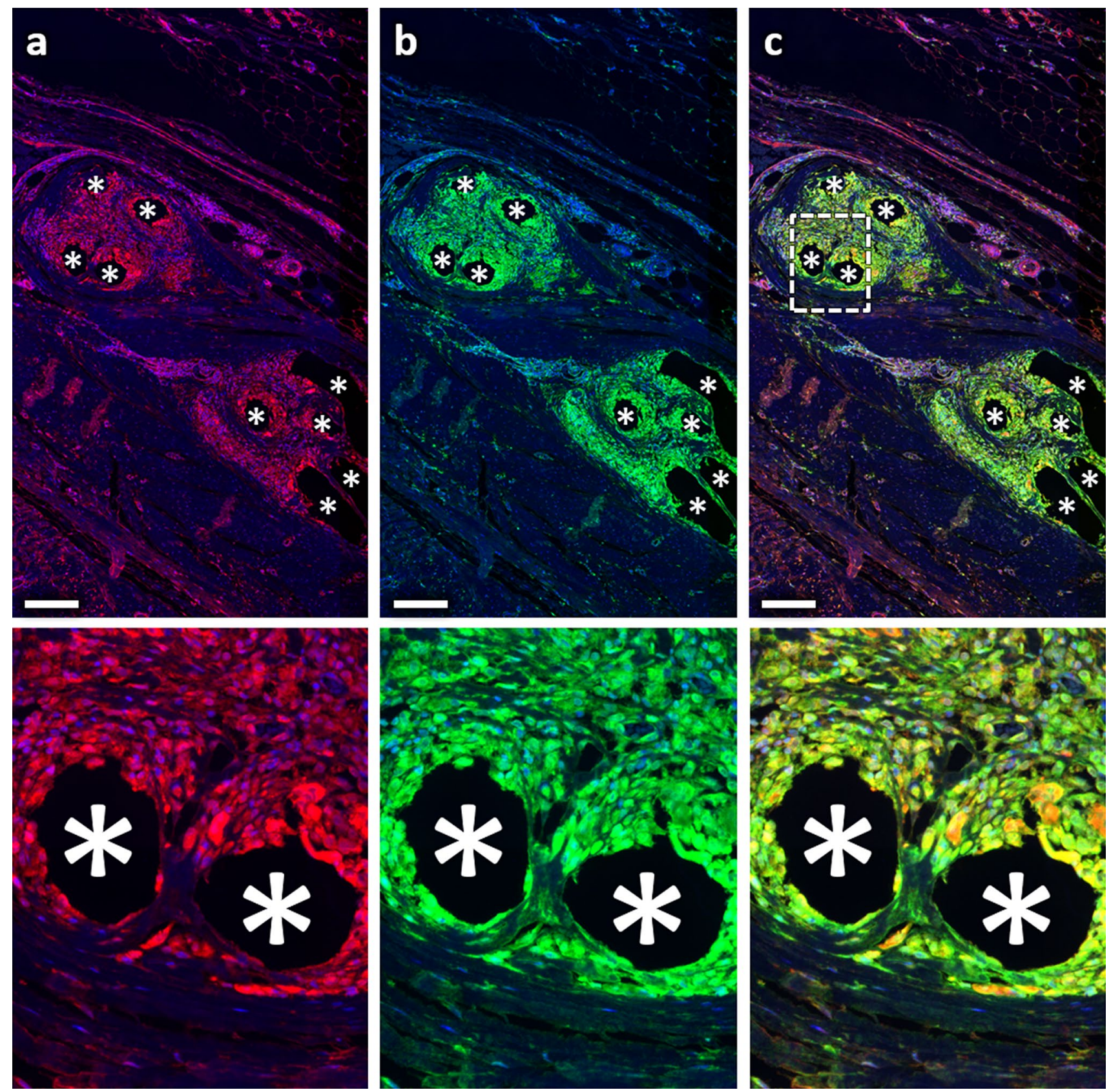

Fig. 12 Immunofluorescence labeling of macrophages (CD68) and MMP-2. a Labeling of MMP-2 (Cy5, red), b CD68 (FITC, green), and $\mathbf{c}$ overlay. Nuclei are labeled with DAPI (blue). Images cor- responding to the dashed rectangular ROI are given below, respectively. Locations of mesh fibers are marked with asterisks, scale bar $=200 \mu \mathrm{m}$. Images from explant \#3 (color figure online) 
Table 5 Spatial distribution of cells and macrophages co-expressing MMP-2 and MMP-8

\begin{tabular}{|c|c|c|c|c|c|c|}
\hline \multirow{2}{*}{$\begin{array}{l}\text { Parameter ( } n=7 \text { PP } \\
\text { meshes) }\end{array}$} & \multicolumn{6}{|c|}{ Distance from Fibers } \\
\hline & $\begin{array}{l}\text { Zone1 } \\
000-050 \mu \mathrm{m}\end{array}$ & $\begin{array}{l}\text { Zone2 } \\
050-100 \mu \mathrm{m}\end{array}$ & $\begin{array}{l}\text { Zone3 } \\
100-150 \mu \mathrm{m}\end{array}$ & $\begin{array}{l}\text { Zone4 } \\
150-200 \mu \mathrm{m}\end{array}$ & $\begin{array}{l}\text { Zone5 } \\
200-250 \mu \mathrm{m}\end{array}$ & $\begin{array}{l}\text { Zone6 } \\
250-350 \mu \mathrm{m}\end{array}$ \\
\hline$\% \mathrm{MMP}-2^{+}$cells & $42.8(5.9)$ & $31.7(5.9)$ & $30.8(6.1)$ & $31.8(5.7)$ & $32.5(6.2)$ & $32.9(5.8)$ \\
\hline $\begin{array}{l}\% \mathrm{CD}^{+} 8^{+} \mathrm{MMP}^{-} 2^{+} \\
\text {cells }\end{array}$ & $38.6(4.7)$ & $21.2(3.8)$ & $16.3(3.4)$ & $13.6(2.7)$ & $12.0(2.7)$ & $10.5(2.6)$ \\
\hline $\begin{array}{l}\% \mathrm{CD} 68^{+} \mathrm{MMP}^{-} 2^{+} / \\
\mathrm{CD} 8^{+}\end{array}$ & $58.1(7.9)$ & $51.6(8.3)$ & $52.8(8.7)$ & $55.2(8.8)$ & $56.2(9.1)$ & $56.9(8.8)$ \\
\hline$\%$ MMP- $8^{+}$cells & $2.5(1.0)$ & $2.2(0.6)$ & $2.2(0.8)$ & $2.9(1.4)$ & $2.8(1.4)$ & $2.6(1.1)$ \\
\hline $\begin{array}{l}\% \mathrm{CD}^{+} 8^{+} \mathrm{MMP}^{-} 8^{+} \\
\text {cells }\end{array}$ & $1.7(0.8)$ & $0.8(0.3)$ & $0.7(0.3)$ & $0.8(0.5)$ & $0.5(0.2)$ & $0.6(0.4)$ \\
\hline $\begin{array}{l}\% \mathrm{CD}^{+} 8^{+} \mathrm{MMP}^{-} 8^{+} / \\
\mathrm{CD}^{+} 8^{+}\end{array}$ & $3.1(1.4)$ & $2.5(0.8)$ & $3.0(1.0)$ & $3.7(1.9)$ & $4.3(1.7)$ & $5.4(3.4)$ \\
\hline
\end{tabular}

Percentages of cells (e.g., MMP2 ${ }^{+}$cells) and macrophages (e.g., CD68 ${ }^{+} \mathrm{MMP}-2^{+}$cells) co-expressing MMPs with respect to all cells, and the proportions of co-expressing macrophages with respect to the total number of macrophages (e.g., $\mathrm{CD} 68^{+} \mathrm{MMP}-2^{+} / \mathrm{CD} 68^{+}$) in each regional zone. The data are presented as mean (SE)

Funding Open Access funding enabled and organized by Projekt DEAL. The support by the Federal Ministry of Education and Research (FKZ 13GW0108B) enabled the acquisition of the TissueGnostics system.

Data availability The raw data required to reproduce these findings are available on request from the authors.

Code availability Not applicable.

\section{Compliance with ethical standards}

Conflict of interest $\mathrm{AD}$ as PhD student is an employee of FEG. PA and LD have no conflicts of interest. UK had research projects and consulting fees in collaboration with the mesh manufacturers Ethicon and FEG; expert testimony at lawsuits concerned with pelvic floor meshes; mesh patents with FEG. The financial disclosures listed result from their expertise, and none of them have tried to influence any part of the work for this manuscript.

Ethical approval All samples used in this study were redundant clinical specimens and their use was approved by the ethics committee at the University Hospital of the RWTH Aachen (EK 239/19).

Consent to participate Not applicable.

Consent to publication Not applicable.

Open Access This article is licensed under a Creative Commons Attribution 4.0 International License, which permits use, sharing, adaptation, distribution and reproduction in any medium or format, as long as you give appropriate credit to the original author(s) and the source, provide a link to the Creative Commons licence, and indicate if changes were made. The images or other third party material in this article are included in the article's Creative Commons licence, unless indicated otherwise in a credit line to the material. If material is not included in the article's Creative Commons licence and your intended use is not permitted by statutory regulation or exceeds the permitted use, you will need to obtain permission directly from the copyright holder. To view a copy of this licence, visit http://creativecommons.org/licenses/by/4.0/.

\section{References}

1. Anderson JM, Rodriguez A, Chang DT (2008) Foreign body reaction to biomaterials. Semin Immunol 20:86-100. https:// doi.org/10.1016/j.smim.2007.11.004

2. Stein M, Keshav S, Harris N, Gordon S (1992) Interleukin 4 potently enhances murine macrophage mannose receptor activity: a marker of alternative immunologic macrophage activation. J Exp Med 176:287-292. https://doi.org/10.1084/jem.176.1.287

3. Mills CD, Kincaid K, Alt JM et al (2000) M-1/M-2 macrophages and the Th1/Th2 paradigm. J Immunol 164:6166-6173. https:// doi.org/10.4049/jimmunol.164.12.6166

4. Wang L, Zhang S, Wu H et al (2019) M2b macrophage polarization and its roles in diseases. J Leukoc Biol 106:345-358. https ://doi.org/10.1002/JLB.3RU1018-378RR

5. Mosser DM, Edwards JP (2008) Exploring the full spectrum of macrophage activation. Nat Rev Immunol 8:958-969. https://doi. org/10.1038/nri2448

6. Krzyszczyk P, Schloss R, Palmer A, Berthiaume F (2018) The role of macrophages in acute and chronic wound healing and interventions to promote pro-wound healing phenotypes. Front Physiol. https://doi.org/10.3389/fphys.2018.00419

7. Brown BN, Mani D, Nolfi AL et al (2015) Characterization of the host inflammatory response following implantation of prolapse mesh in rhesus macaque. Am J Obstet Gynecol 213:668.e1-668. e10. https://doi.org/10.1016/j.ajog.2015.08.002

8. Wolf MT, Dearth CL, Ranallo CA et al (2014) Macrophage polarization in response to ECM coated polypropylene mesh. Biomaterials 35:6838-6849. https://doi.org/10.1016/j.biomaterials.2014.04.115

9. Nolfi AL, Brown BN, Liang R et al (2016) Host response to synthetic mesh in women with mesh complications. Am J Obstet Gynecol 215:206.e1-206.e8. https://doi.org/10.1016/j.ajog.2016.04.008

10. Spiller KL, Koh TJ (2017) Macrophage-based therapeutic strategies in regenerative medicine. Adv Drug Deliv Rev 122:74-83. https:// doi.org/10.1016/j.addr.2017.05.010

11. Hachim D, LoPresti ST, Yates CC, Brown BN (2017) Shifts in macrophage phenotype at the biomaterial interface via IL-4 eluting coatings are associated with improved implant integration. Biomaterials 112:95-107. https://doi.org/10.1016/j.biomateria 1s.2016.10.019

12. Hou J, Shi J, Chen L et al (2018) M2 macrophages promote myofibroblast differentiation of LR-MSCs and are associated with 
pulmonary fibrogenesis. Cell Commun Signal 16:89. https://doi. org/10.1186/s12964-018-0300-8

13. Klinge U, Dievernich A, Tolba R et al (2020) CD68+ macrophages as crucial components of the foreign body reaction demonstrate an unconventional pattern of functional markers quantified by analysis with double fluorescence staining. J Biomed Mater Res JBM B. https://doi.org/10.1002/jbm.b.34639

14. Brown BN, Londono R, Tottey S et al (2012) Macrophage phenotype as a predictor of constructive remodeling following the implantation of biologically derived surgical mesh materials. Acta Biomater 8:978-987. https://doi.org/10.1016/j.actbio.2011.11.031

15. Pierce LM, Rao A, Baumann SS et al (2009) Long-term histologic response to synthetic and biologic graft materials implanted in the vagina and abdomen of a rabbit model. Am J Obstet Gynecol 200:546.e1-546.e8. https://doi.org/10.1016/j.ajog.2008.12.040

16. Pechkovsky DV, Prasse A, Kollert F et al (2010) Alternatively activated alveolar macrophages in pulmonary fibrosis-mediator production and intracellular signal transduction. Clin Immunol 137:89-101. https://doi.org/10.1016/j.clim.2010.06.017

17. Venosa A, Malaviya R, Choi $\mathrm{H}$ et al (2016) Characterization of distinct macrophage subpopulations during nitrogen mustard-induced lung injury and fibrosis. Am J Respir Cell Mol Biol 54:436-446. https://doi.org/10.1165/rcmb.2015-0120OC

18. Wynn T, Barron L (2010) Macrophages: master regulators of inflammation and fibrosis. Semin Liver Dis 30:245-257. https:// doi.org/10.1055/s-0030-1255354

19. Murray PJ, Wynn TA (2011) Protective and pathogenic functions of macrophage subsets. Nat Rev Immunol 11:723-737. https://doi. org/10.1038/nri3073

20. Madsen DH, Leonard D, Masedunskas A et al (2013) M2-like macrophages are responsible for collagen degradation through a mannose receptor-mediated pathway. J Cell Biol 202:951-966. https:// doi.org/10.1083/jcb.201301081

21. Simões FC, Cahill TJ, Kenyon A et al (2020) Macrophages directly contribute collagen to scar formation during zebrafish heart regeneration and mouse heart repair. Nat Commun 11:600. https://doi. org/10.1038/s41467-019-14263-2
22. Schnoor M, Cullen P, Lorkowski J et al (2008) Production of type VI collagen by human macrophages: a new dimension in macrophage functional heterogeneity. J Immunol 180:5707-5719. https://doi. org/10.4049/jimmunol.180.8.5707

23. Jansen PL, Kever M, Rosch R et al (2007) Polymeric meshes induce zonal regulation of matrix metalloproteinase- 2 gene expression by macrophages and fibroblasts. FASEB J 21:1047-1057. https://doi. org/10.1096/fj.06-6755com

24. Binnebösel M, von Trotha KT, Ricken C et al (2012) Gentamicin supplemented polyvinylidenfluoride mesh materials enhance tissue integration due to a transcriptionally reduced MMP-2 protein expression. BMC Surg 12:1. https://doi.org/10.1186/1471-2482-12-1

25. Vacek T, Rahman S, Yu S et al (2015) Matrix metalloproteinases in atherosclerosis: role of nitric oxide, hydrogen sulfide, homocysteine, and polymorphisms. VHRM. https://doi.org/10.2147/VHRM.S6841 5

26. Davies LC, Taylor PR (2015) Tissue-resident macrophages: then and now. Immunology 144:541-548. https://doi.org/10.1111/imm.12451

27. Rőszer T (2015) Understanding the mysterious M2 macrophage through activation markers and effector mechanisms. Mediators Inflamm 2015:1-16. https://doi.org/10.1155/2015/816460

28. Reinartz S, Schumann T, Finkernagel F et al (2014) Mixed-polarization phenotype of ascites-associated macrophages in human ovarian carcinoma: correlation of CD163 expression, cytokine levels and early relapse: macrophages in human ovarian carcinoma. Int J Cancer 134:32-42. https://doi.org/10.1002/ijc.28335

29. Brown BN, Valentin JE, Stewart-Akers AM et al (2009) Macrophage phenotype and remodeling outcomes in response to biologic scaffolds with and without a cellular component. Biomaterials 30:14821491. https://doi.org/10.1016/j.biomaterials.2008.11.040

Publisher's Note Springer Nature remains neutral with regard to jurisdictional claims in published maps and institutional affiliations. 